Ann. Biol. anim. Bioch. Biophys., 1979, 19 (4 B), 1297-1306.

\title{
The regulation of androgen and estrogen formation in fetal gonads
}

\author{
par F. W. GEORGE, J. D. WILSON \\ The Eugene McDermott Center for Growth and Development and the Department \\ of Internal Medicine, The University of Texas Southwestern Medical School, \\ Dallas, Texas 75235, USA.
}

Summary. Several aspects of the functional development of the testis and ovary have been characterized in the fetal rabbit. First, the capacity of the fetal ovary to form $17 \beta$-estradiol develops at the same time in embryogenesis as the onset of testosterone formation in the fetal testis. Second, both fetal ovaries and testes have the capacity to form these steroid hormones from cholesterol de novo. Third, the enzymatic differentiation of the fetal testis occurs at the expected time in organ culture suggesting that this aspect of development is not hormone-induced. Fourth, gonadotropin receptors appear in testes concomitant with the initial rise in testosierone content but are virtually absent in ovaries throughout gestation. However, the onset of testosterone synthesis and the initial rise in testosterone content in the fetal testis do not appear to be coupled to gonadotropin stimulation since hCG does not stimulate testosterone formation until late in embryogenesis.

The studies of Jost $(1953,1960,1970)$ established that the secretion of androgen by the fetal testis plays a vital role in the differentiation of the male internal and external genitalia. In fetal rabbit (Lipsett and Tullner, 1965 ; Wilson and Siiteri, 1973), sheep (Attal, 1969), and man (Siiteri and Wilson, 1974) the onset of testosterone formation by the testis occurs just prior to the onset of male differentiation of the urogenital tract. Further support for the primary role of androgen in male phenotypic differentiation has been established by characterization of several single gene mutations in humans that cause abnormal synthesis or action of the hormone and prevent normal male sexual development (Goldstein and Wilson, 1974). In contrast to the well established role of androgen in male phenotypic development, little is known about the endocrine function of the fetal ovary.

The following studies were performed to define three issues in the regulation of steroidogenesis by fetal gonads. First, when does the onset of endocrine function commence in the feial ovary? Second, what is the source of precursors for steroidogenesis in fetal gonads? Third, what regulates the testosterone synthesis in fetal testes at the time of its onset? 


\section{Methods.}

Rabbit studies. - New Zealand white rabbits were mated during as $2 \mathrm{~h}$ period in the late afternoon of a day that was arbitrarily designated as day 0 for the purpose of timing the pregnancy. At various times thereafter the does were killed, and the embryos were removed and placed on ice. The gonads were dissected from the fetuses and used immediately for acute incubation studies.

Incubation of fetal tissues with $\left[7_{-3} \mathrm{H}\right]$ pregnenolone and the separation of the metabolites of the reaction by celite column chromatography and purification by thin layer chromatography are described elsewhere (George ef al., in press). $3 \beta$-Hydroxysteroid dehydrogenase- $\Delta^{4,5}$-isomerase activity was estimated by measuring the rate of conversion of $\left[7-{ }^{3} \mathrm{H}\right]$ dehydroepiandrosterone to androstenedione and testosterone (George ef al., 1978a). For organ culture studies day 16 undifferentiated fetal gonads were cultured in a chemically defined medium without serum as described (George et al., 1978a). The measurement of gonadotropin binding in fetal gonads and of testosterone and adenosine-3',5'-cyclic monophosphate (cyclic AMP) by radioimmunoassay have also been described (Catt ef al., 1975 ; Dufau et al., 1973). For the estimation of cholesterol side-chain cleavage activity, 5 steroids (pregnenolone, progesterone, dehydroepiandrosterone, 5-androstene-3 $\beta, 17 \beta$-diol [ $\Delta^{5}$-androstenediol] and testosterone) were measured before and after a $2 \mathrm{~h}$ in vifro incubation. The separation of these 5 steroids by celite column chromatography and their subsequent measurement by radioimmunoassay are described elsewhere (George ef al., in press).

Human studies. - Human fetuses of various gestational ages were obtained either from patients who were subjected to hysterectomy during pregnancy because of some medical indication or from patients undergoing abortions by suction curretage. In all instances informed consent was obtained for the study of the embryonic tissues, and all embryos were grossly normal. Less than $2 \mathrm{~h}$ elapsed between the time of death and the commencement of the study. Fetal tissues were incubated with either $\left[7-{ }^{3} \mathrm{H}\right]$ pregnenolone for the estimation of testosterone formation (Siiteri and Wilson, 1974), or with $\left[1,2,6,7-{ }^{3} \mathrm{H}\right]$ androstenedione or $\left[1,2,6,7-{ }^{3} \mathrm{H}\right]$ testosterone for the measurement of estrogen formation (George and Wilson, 1978). Reaction products were purified by a combination of celite column and thin-layer chromatography (Siiteri and Wilson, 1974 ; George and Wilson, 1978).

\section{Results.}

Fetal ovarian differentiation. - In a series of studies designed to detect small amounts of estrogens formed from radioactive androgens by fetal rabbit tissues, we demonstrated that the fetal ovary develops the enzymatic capacity to synthesize estrogens from androgens at precisely the time that the fetal testis develops the capacity to form testosterone (Milewich et al., 1977). More recently we have measured the ability of fetal rabbit ovaries and testes to convert $\left[7^{3} \mathrm{H}\right]$ pregnenolone to testosterone, $\Delta^{5}$-androstenediol and $17 \beta$-estradiol at various times during gestation. 
The fetal testis acquired the ability to form testosterone by day 18 of gestation (fig. 1, panel A), where as the fetal ovary showed little capacity for testosterone synthesis at any time studied. In contrast, as depicted in panel $C, 17 \beta$-estradiol formation was defected only in the fetal ovary. Although the rate of estradiol formation by the ovary was approximately 50-fold lower than the rate of testosterone synthesis by the testis, the onset of characteristic hormone synthesis for each tissue occurs at precisely the same time. Furthermore, this experiment established that both fetal ovaries and testes acquire the complete enzymatic machinery to form characteristic hormones from pregnenolone. Panel B depicts the capacity of fetal gonads to synthesize $\Delta^{5}$-androstenediol from pregnenolone. The fact that $\Delta^{5}$-androstenediol accumulated in the fetal ovary but not in the fetal testis indicates that the fetal ovaries have a major block in the steroidogenic pathway at the level of the $3 \beta$-hydroxysteroid dehydrogenase- $\Delta^{4,5_{-}}$ isomerase enzyme. Nonetheless, as is evident from the insert to panel A, there was sufficient testosterone formed in fetal ovaries to provide testosterone substrate for estradiol synthesis.
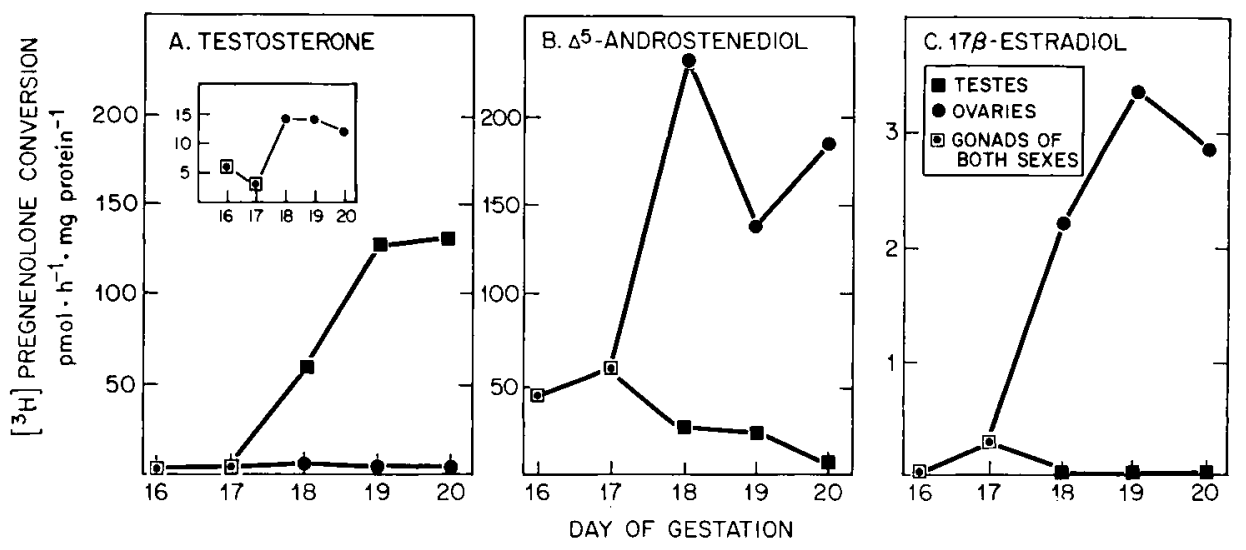

FIG. 1. - Steroid hormone formation from $\left[7^{3} \mathrm{H}\right]$ pregnenolone in fetal rabbit gonads. Fetal gonads at various stages of development were incubated for $2 \mathrm{~h}$ with $5 \mu \mathrm{M}\left[7_{-3} \mathrm{H}\right]$ pregnenolone in a fotal volume of $0.2 \mathrm{ml}$. Following the incubation the steroids were extracted, and testosterone, $\Delta^{5}$ androstenediol and $17 \beta$-estradiol were isolated by a combination of celite column and thin-layer chromatographic procedures. The isolated steroids were then purified by multiple thin-layer chromatographic procedures. In some instances the steroids isolated after the final thin-layer procedure were recrystallized to establish radio-chemical purity (George ef al., in press).

We have also shown that these enzymatic activities have physiological significance by demonstrating that the testosterone and $17 \beta$-estradiol content of fetal rabbit gonads at various stages of gestational development (as assessed by radioimmunoassay) parallel the enzymatic capacity for estrogen synthesis (George ef al., 1978b). The fact that the estrogen content of the fetal ovary increases at the same time as the testosterone content of the fetal testis establishes that the endocrine differentiation of the two tissues is essentially complete early in embryogenesis.

Similar findings (depicied in fig. 2) have been obtained in the human fetal gonad. The onset of estrogen synthesis by the human fetal ovary was found to occur at 8-10 weeks 
of gestation (George and Wilson, 1978) concomitant with the onset of testosterone synthesis in the human fetal testis (Siiteri and Wilson, 1974).

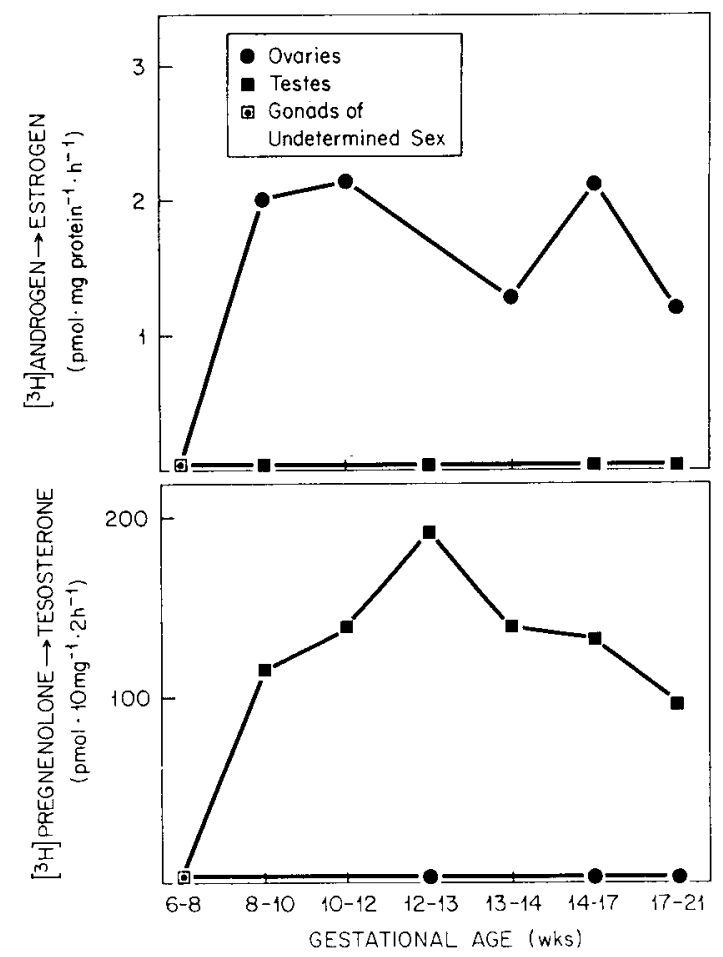

FIG. 2. - Steroid hormone formation in human fetal gonads. Total estrogen (17 $\beta$-estradiol plus estrone) formation (upper panel) was assessed in incubations of human fetal gonads with either $0.5 \mu \mathrm{M}$ $\left[1,2,6,7-{ }^{3} \mathrm{H}\right]$ androstenedione or $\left[1,2,6,7{ }^{3} \mathrm{H}\right]$ testosterone and is expressed per $\mathrm{mg}$ protein. The estrogens were isolated and purified by celite column chromatography and multiple thinlayer chromatography steps. Testosterone formation (lower panel) was assessed following incubations with $\left[{ }^{-3} \mathrm{H}\right]$-pregnenolone as described (Siiferi and Wilson, 1974) and is expressed per $10 \mathrm{mg}$ tissue wet weight. Data were taken from George and Wilson (1978) and Siiteri and Wilson (1974).

Source of substrates for steroidogenesis. - Given the fact that fetal ovaries and testes differentiate enzymatically at the same time, we were interested in determining the source of the steroid substrates (pregnenolone and/or progesterone) that are utilized for testosterone and estrogen synthesis. Figure 3 depicts two possible sources of these substrates. On the one hand, $\mathrm{C}_{21}$-steroids such as pregnenolone could be derived from the side-chain cleavage of cholesterol as in the mature gonad. a step that is presumably regulated by gonadotropins (Marsh, 1975). Alternatively, the placenta could provide $\mathrm{C}_{21}$-steroids to the fetal circulation and ultimately to the ovary and testis, thus circumventing the necessity for their formation within the gonad. To examine this question we measured the capacity for cholesterol side-chain cleavage to $C_{21}$-steroids in embryonic gonads. If steroid hormones are synthesized de novo from the first 
in the gonads, cholesterol side-chain cleavage should be demonstrable before the onset of testosterone and estrogen synthesis. On the other hand, if $\mathrm{C}_{21}$-steroids are supplied from outside the gonads, cholesterol side-chain cleavage activity might not develop until late in embryogenesis. Cholesterol side-chain cleavage activity was

(1)

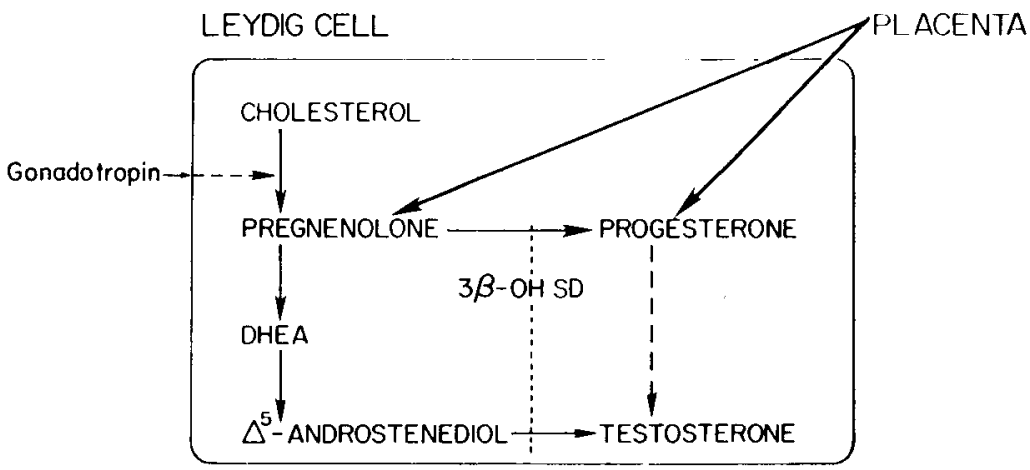

FIG. 3. - Two possible sources of $\mathrm{C}_{21}$-steroids to serve as intermediates inandrogen and estrogen biosynthesis in the fetal gonads.

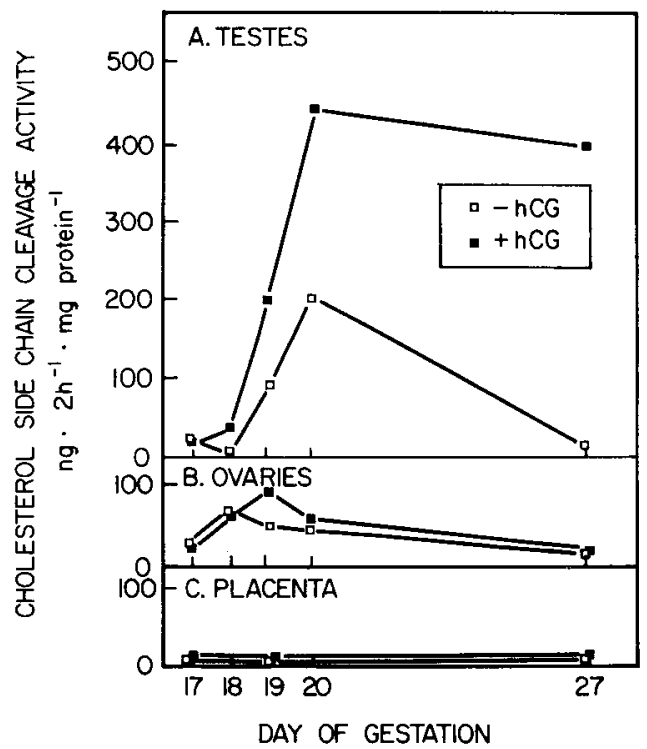

FIG. 4. - Developmental pattern of cholesterol side-chain cleavage activity in fetal gonods. Fetal rabbit gonads at various stages of development were incubated for $2 \mathrm{~h}$ in the presence or absence of $10 \mathrm{lU} / \mathrm{ml}$ hCG. Following the incubation the steroids were extracted from the incubation mixture, and five steroids (pregnenolone, progesterone, dehydroepiandrosterone, $\Delta^{5}$-androstenediol, and testosterone) were separated by celite column chromatography and quantiated by radioimmunoassay (George et al., in press). Cholesterol side-chain cleavage activity is expressed as the net amount (total amount of 5 steroids produced in $2 \mathrm{~h}$ minus total amount present at time 0 ) of steroids produced in the $2 \mathrm{~h}$ incubation period. 
expressed as the net amount of five steroids (pregnenolone, progesterone, dehydroepiandrosterone, $\Delta^{5}$-androstenediol, and testosterone) produced by fetal gonads in a $2 \mathrm{~h}$ in vitro incubation. Since progesterone and pregnenolone levels were low in all fetal tissues examined, including placenta, we concluded that no pool of $\mathrm{C}_{21}$-steroids that could serve as substrate for steroidogenesis exists in these tissues. Furthermore, as depicted in figure 4, cholesterol side-chain cleavage activity was low, but detectible, in day 17 gonads, increased to approximately $200 \mathrm{ng} \cdot 2 \mathrm{~h}^{-1} \cdot \mathrm{mg}$ protein ${ }^{-1}$ in day 20 unstimulated fetal testis (panel A), and thereafter decreased at day 27 of gestation. The ability of hCG to stimulate this activity in testes was clearly evident from day 18 onward. In contrast, although cholesterol side-chain cleavage in fetal ovaries (fig. 4, panel B) was initially greater than in fetal testes, hCG did not stimulate this activity. The placenta appears to lack the capacity for side-chain cleavage of cholesterol (fig. 4, panel C). Thus, in the rabbit embryo all steroid hormone synthesis within the gonads is probably derived de novo from cholesterol from the very first.

Regulation of testosterone synthesis by the fetal testis. - To gain insight into what factors regulate steroidogenesis in the fetal gonad at the onset of endocrine function, the developmental pattern of $3 \beta$-hydroxysteroid dehydrogenase activity was characterized in fetal rabbit gonads explanted in organ culture prior to enzymatic differentiation. As shown in figure 5, when gonads were cultured from day 16 of gestation, $3 \beta$-hydroxysteroid dehydrogenase activity appeared at the expected time, corresponding to day 18 in vivo. After 4 days in organ culture, the enzyme activity was approximately half that observed in the corresponding control testes. This is the value that would be predicted if development in vitro were completely normal since only about half of the cultured indifferent gonads were destined to be testes. If can be concluded, therefore, that the appearance of the $3 \beta$-hydroxysteroid dehydrogenase- $\Delta^{4,5}$-isomerase activity in the rabbit testis and consequently the ability to convert C-21 steroids to testosterone is probably the result of inherent programming of the fetal Leydig cell rather than to hormonal or substrate induction at the time of gonadal differentiation (Analogous studies of the pattern of aromatase activity in the fetal ovary in organ culture have not yet been performed.) However, the fact that the enzyme that is ratelimiting in vivo in testosterone synthesis in the rabbit develops independent of hormonal regulation does not necessarily imply that net hormone formation itself is also independent of such regulation. Indeed, the formation of $C_{21}$ precursors and hence androgen synthesis might well be under regulation.

The possibility that gonadotropins might be involved in the onset of testosterone synthesis was suggested by the finding that $\mathrm{LH} / \mathrm{hCG}$ receptors appeared in the fetal rabbit testis at approximately the same time as the onset of testosterone synthesis on day 18 of gestation (Catt et al., 1975 ; George et al., 1978a). This corresponds closely to the ability of hCG to stimulate cholesterol side-chain cleavage activity (fig. 4). In contrast, the fetal ovaries are devoid of LH/hCG receptors throughout gestation, and in fetal ovaries hCG does not enhance cholesterol side-chain cleavage (fig. 4).

Next, we determined the cyclic AMP and testosterone responses to a saturating concentration of hCG in fetal ovaries and testes. As is evident (fig. 6, upper-left), fetal testes respond to hCG stimulation by synthesizing cyclic AMP from day 18 of gestation, again corresponding to the time of initial appearance of gonadotropin receptors and 


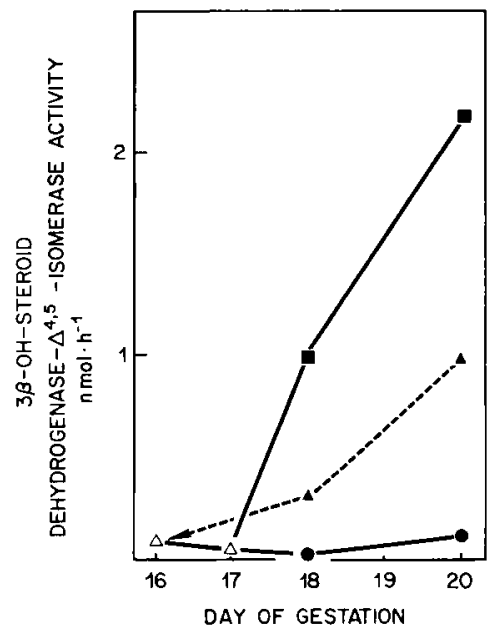

FIG. 5. - Developmental pattern of 3ß-hydroxysteroid dehydrogenase- $\Delta^{4,5}$-isomerase activity and in organ culture. Gonadal explants from day $16(\ldots \ldots A)$ fetuses were cultured and harvested at times corresponding to days 18 and 20 in vivo. Cultured and in vivo control gonads were incubated with $5 \mu \mathrm{M}\left[7^{3} \mathrm{H}\right]$ dehydroepiandrosterone, and $3 \beta$-hydroxysteroid dehydrogenase activity was determined as described (George et al., 1978a). Gonads of undetermined sex ( $\Delta$ ), cultured gonads $(\Delta)$, fetal ovaries (๑), fetal testes ( $\bullet$ ). Data adapted from George et al. (1978a). Data 15 expressed per $\mathrm{mg}$ protein.

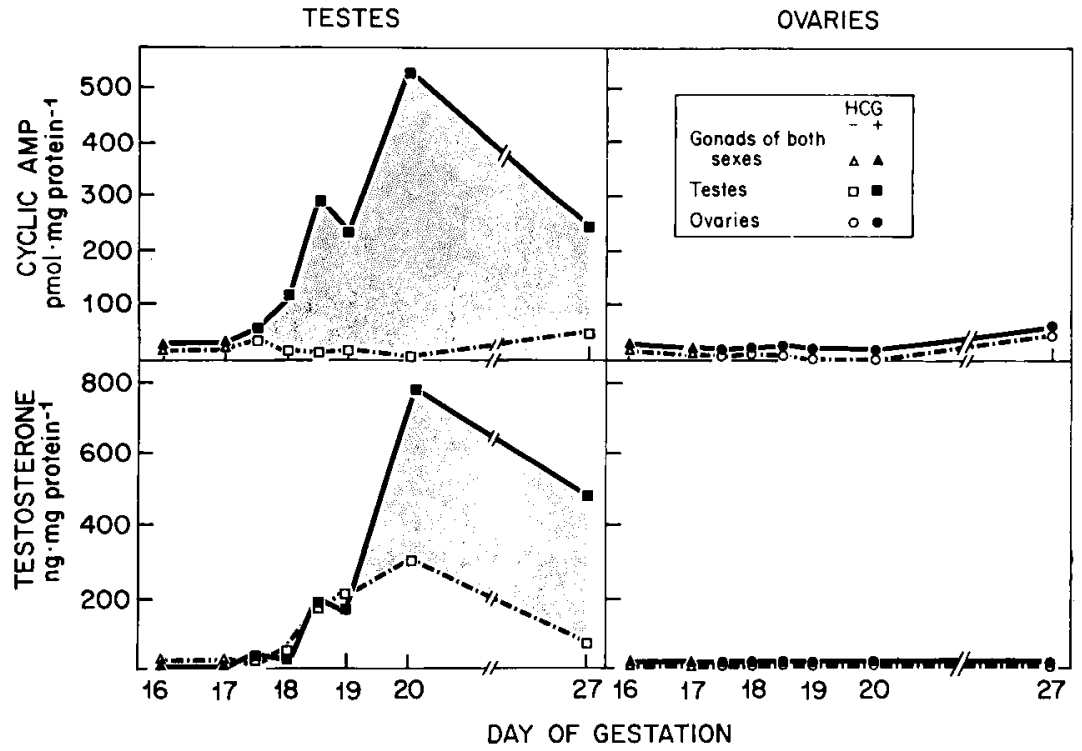

FIG. 6. - In vitro cyclic AMP and testosterone responses of fetal rabbit gonads to hCG. Fetal rabbit gonads at various stages of development were incubated for $3 \mathrm{~h}$ in the presence or absence of 10 IU hCG Cyclic AMP (Dufau et al., 1973) and testosterone (Catt et al.. 1975) were measured by radioimmunoassay as described. Reprinted from George et al. (1978a). 
the onset of testosterone synthesis, whereas the fetal ovary (fig. 6, upper-right) does not show a cAMP-response to hCG at any time. Thus, the fact that gonadotropin binding in the fetal testis is demonstrable from approximately day 18 of gestation and that hCG stimulates cyclic AMP formation and cholesterol side-chain cleavage from day 18 indicates that the $\mathrm{LH} / \mathrm{hCG}$ receptor is coupled to at least one phase of steroidogenesis from the time of its initial development.

The findings in regard to testosterone formation in the presence or absence of hCG were strikingly different (fig. 6, lower-left). Although the increase in testosterone corresponded closely to the known increase in $3 \beta$-hydroxysteroid dehydrogenase activity (fig. 5), the appearance of adenylate cyclase-coupled gonadotropin receptors (fig. 6), and development of side-chain cleavage responsiveness to hCG (fig. 4), enhancement of testosterone synthesis by hCG was not demonstrable until after day 19 of gestation. Thus, either endogenous gonadotropins already enhance testosterone synthesis maximally, or testosterone synthesis is independent of gonadotropin control for approximately the first 2 days after its initial onset.

\section{Discussion.}

These studies have provided insight into the endocrine differentiation of the gonads that takes place at the time of phenotypic sexual differentiation. First, the finding that the fetal rabbit ovary acquires the enzymatic capacity to synthesize $17 \beta$-estradiol at the same time that the fetal testis acquires the capacity to form testosterone is of fundamental interest. On the basis of histological studies, it has been presumed that the ovary differentiates later than the testis (Gilman, 1948), but it is now clear that in terms of the acquisition of the enzymatic activities that allow these tissues to serve as distinct endocrine organs differentiation of the indifferent gonad into an ovary or a testis takes place almost at the same time. The fact that the fetal rabbit ovary acquires the capacity to synthesize estrogens from pregnenolone does not necessarily imply that estrogen synthesis by the fetal ovary is important for female phenotypic differentiation, but it is conceivable that the estrogen formed by the fetal ovary may be important for development of the ovary itself.

Second, both fetal ovaries and testes have the capacity to form steroid hormones de novo from cholesterol, and consequently it is unlikely that the placenta of the rabbit provides C-21 precursors to the fetal circulation and hence to the gonads for steroidogenesis. The fact that cholesterol side-chain cleavage activity was not stimulated by hCG in incubations with fetal ovaries, whereas hCG stimulates this activity from day 18 of gestation in fetal testes, is consistent with the presence of LH/hCG receptors in the fetal testis at day 18 and the absence of $\mathrm{LH} / \mathrm{hCG}$ receptors in the ovary.

Third, the present findings, as well as those of Picon in fetal rats (1967) and Brinkmann in fetal guinea pigs (1976), indicate that the enzymatic differentiation of the fetal testis occurs in organ culture. This suggests that development of the capacity to form testosterone is not induced hormonally but, rather, is due to the inherent genetic programming of the fetal Leydig cell.

Finally, it is of interest that both the fetal ovary and testis demonstrate considerable cholesterol side-chain cleavage activity in the absence of gonadotropin stimula- 
tion and that ovarian cholesterol side-chain cleavage activity which is initially higher than that in fetal testis, occurs despite the absence of detectible LH/hCG receptors. These findings, coupled with the fact that initial testosterone synthesis in the fetal testis occurs at the same rate in the absence as in the presence of hCG, suggest that the onset of testosterone synthesis in the fetal rabbit testis is independent of gonadotropin stimulation. Picon (1976) has arrived at a similar conclusion in studies involving the in vitro incubation of fetal rat testes. However, this interpretation cannot be viewed as conclusive. In the mature rat testis, occupancy of only 1 p. 100 of the gonadotropin receptors can result in maximal stimulation of testosterone synthesis (Mendelson ef al., 1975). It remains possible that between days 18 and 19 of gestation, a limited number of gonadotropin receptors, functionally coupled to testosterone synthesis, are saturated with endogenous gonadotropins and hence cannot be stimulated further by exogenous hCG. To resolve this issue, it will be necessary to analyze the nature and quantity of circulating and bound gonadotropins in the fetal rabbit testis during this critical phase of development.

In conclusion, although the mechanism by which cholesterol side-chain cleavage is initially independent of, and then dependent on, gonadotropin action is unclear, we have established three principle differences in fetal ovaries and testes that relate to the onsef of steroidogenic function. First, as depicted in figure 7, by day 18 in the

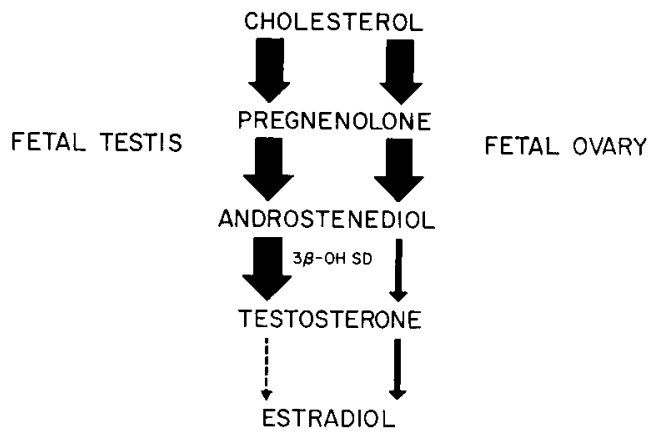

FIG. 7. - Pathway of steroid hormone synthesis from cholesterol in day 18 fetal rabbit gonads.

fetal rabbit, although both fetal ovaries and fetal testes acquire the complete enzymatic machinery to form testosterone from cholesterol, considerably more $3 \beta$-hydroxysteroid dehydrogenase activity develops in the fetal testis than in the fetal ovary. Second,estrogen synthesis is only demonstrable in fetal ovaries. And third LH/hCG receptors are only detectible in fetal testes. The physiologic significance of these receptors in regulating the onset of testosterone synthesis in the fetal testes remains to be proven.

4th Workshop on « Development and maturation of the reproductive organs and functions 》 Luynes, France, octobre 1978.

Acknowledgments. - This research was supported by Grant AM 03892 from the NIH, and Dr. George was the recipient of a fellowship under NIH training grant CA 05200 during a portion of these studies. 
Résumé. Divers aspects du développement fonctionnel du testicule et de l'ovaire du fœtus ont été caractérisés chez le Lapin :

1) la capacité de l'ovaire fœil à synthétiser de l'oestradiol apparaît au même moment de l'embryogenèse que, dans le testicule, la formation de testostérone ;

2) à la fois l'ovaire et le testicule ont la capacité de produire ces hormones stéroïdes de novo à partir du cholestérol ;

3) la différenciation des enzymes testiculaires se produit en culture au moment escompté, ce qui suggère que cet aspect du développement n'est pas hormonodépendant ;

4) les récepteurs des gonadotropines apparaissent dans le testicule en même temps que se produit l'élévation de la sécrétion de testostérone, mais ces récepteurs font défaut dans l'ovaire pendant toute la gestation. Cependant, le début de la synthèse de testostérone et sa poussée de sécrétion initiale n'apparaissent pas liés à une stimulation gonadotrope, puisque HCG ne stimule la formation de testostérone que tardivement au cours de l'embryogenèse.

\section{References}

ATTAL J., 1969. Levels of testosterone, androstenedione, estrone and estradiol-17 $\beta$ in the testes of fetal sheep. Endocrinology, 85, 280-289.

BRINKMANN A. O., 1976. In vitro synthesis and secretion of testosterone by fotal testes of rats and guinea pigs under the influence of luteinizing hormone. J. Endocrinol., 72, $19 \mathrm{P}$.

CATT K. J., DUFAU M. L., NEAVES W. B., WALSH P. C., WILSON J. D., 1975. Lh-hCG receptors and testosterone content during differentiation of the testis in the rabbit embryo. Endocrinology, 97, 1157-1165.

DUFAU M. L., WATANABE K., CATT K. J., 1973. Stimulation of cyclic AMP production by the rat testis during incubation with hCG in vitro. Endocrinology, 92, 6-11.

GEORGE F. W., CATT K. J., NEAVES W. B., WILSON J. D., 1978a. Studies on the regulation of testosterone synthesis in the rabbit fetal testis. Endocrinology, 102, 665-673.

GEORGE F. W., MILEWICH L., WILSON J. D., 1978b. Oestrogen content of the embryonic rabbit ovary. Nature, 274, $172-173$.

GEORGE F. W., WILSON J. D., 1978. Conversion of androgen to estrogen by the human fetal ovary. J. clin. Endocrinol. Metab., 47, 550-555.

GEORGE F. W., SIMPSON E. R., MILEWICH L., WILSON J. D., 1979. Studies on the regulation of the onset of steroid hormone biosynthesis in fetal rabbit gonads. Endocrinology (in press).

GILLMAN J., 1948. The development of the gonads in man, with a consideration of the role of fetal endocrines and the histogenesis of ovarian tumors. Contrib. Embryol., 32, 83-131. Carnegie Inst. Washington Publ. 575.

GOLDSTEIN J. L., WILSON J. D., 1974. Hereditary disorders of sexual development in man, 165-173. In MOTULSKY A. G., LENTZ W., Birth defects. Proceed 4th int. Conf. (Vienna), Excerpta med. Found., Amsterdam.

JOST A., 1953. Problems in fetal endocrinology : the gonadal and hypophyseal hormones. Recent Prog. Hor. Res., 8, 379-418.

JOST A., 1960. The role of fetal hormones in prenatal development. Harvey Lect. Ser., 55, 201-226.

JOST A., 1970. Hormonal factors in the sex differentiation of the mammalian fœtus. Phil Trans. r. Soc. Lond B, 259, 119-130.

LIPSETT M. B., TULLNER W. W., 1965. Testosterone synthesis by the fetal rabbit gonad. Endocrinology, 77, 273-277.

MARSH J. M., 1975. The role of cyclic AMP in gonadal function. Adv. Cyclic Nucleotide Res., 6, $137-199$.

MENDELSON C., DUFAU M., CATT K., 1975. Gonadotropin binding and stimulation of cyclic adenosine 3' : 5'-monophosphate and testosterone production in isolated Leydig cells. $J$. biol. Chem., 250, 8818-8823.

MILEWICH L., GEORGE F. W., WILSON J. D., 1977. Estrogen formation by the ovary of the rabbit embryo. Endocrinology, 100, 187-196.

PICON R., 1967. Activité $\Delta^{5}-3 \beta$-hydroxystéroide déshydrogénasique du testicule fœetal de rat in vitro. Arch. Anat. microsc., 56, 281-290.

PICON R., 1976. Testosterone secretion by fotal rat testes in vitro. J. Endocrinol., 71, 231-238.

SIITERI P. K., WILSON J. D., 1974. Testosterone formation and metabolism during male sexual differentiation in the human embryo. J. clin. Endocrinol. Metab., 38, 113-125.

WILSON J. D., SIITERI P. K., 1973. Developmental pattern of testosterone synthesis in the fetal gonad of the rabbit. Endocrinology, 92, 1182-1191. 